\title{
AUDITORÍA DEL CAPITAL INTELECTUAL
}

\author{
Dr. JULIO V. FLORES KONJA(*) \\ CPC'ALAN E. ROZA'S FLORES (**)
}

\begin{abstract}
La Auditoría del Capital Intelectual, como toda auditoría, es un examen objetivo, sistemático y profesional cuya finalidad es evaluar, examinar y emitir un informe sobre el capital intelectual de las organizaciones. Pero, ¿qué es el Capital Intelectual?, ¿en qué consiste?, ¿cómo se registra?, ¿aparece en la contabilidad de las empresas? Una respuesta a estas interrogantes constituye el presente artículo.
\end{abstract}

\section{Capital Intelectual}

Comprende el conjunto de elementos de naturaleza inmaterial que son imprescindibles para que la empresa lleve a cabo su actividad en un entorno como el actual, basado en una economía del conocimiento. A. Brooking en su obra El capital intelectual: el principal activo de las empresas del tercer milenio establece los siguientes componentes del capital intelectual.

\section{- Activos del mercado}

Comprende marcas, denominación social de la empresa, fidelidad de la clientela, respetabilidad del negocio, reserva de pedidos, canales de distribución, licencias y franquicias. En definitiva, son elementos que propor- cionan a la empresa una ventaja competitiva en el mercado.

\section{- Activos de propiedad intelectual Incluyen elementos como el saber hacer de la empresa, secretos de fabricación, derechos de autor, patentes, derechos de diseño y marcas de fábrica y servicios.}

\section{- Activos de infraestructura}

Comprende elementos que definen la forma de trabajo en la organización: filosofia de gestión, cultura corporativa, procesos de gestión, tecnología de la información, sistemas de interconexiones y relaciones financieras.

\section{-Activos centrados en el individuo} Incluyen elementos tales como el nivel de estudios alcanzado, cualificaciones profesionales, conocimientos técnicos relacionados con el trabajo, psicometria y competencias asociadas con el trabajo. A diferencia de los activos de mercado, de propiedad intelectual y de infraestructura, no pueden ser propiedad de la empresa.

Es imprescindible para la empresa actual conocer los fundamentos que 
comprenden su capital intelectual, establecer cuál es la situación actual de los mismos y, en la medida que sea posible, su valoración.

Hasta ahora la norma contable no admite la posibilidad de incluir el elemento más valioso para la empresa (su capital intelectual) en los estados financieros anuales. La idea es la siguiente: Como no existe una medida objetiva que permita valorar tales elementos, entonces se les asigna un valor cero. Es decir, que contablemente no existen dichos elementos, sin embargo, en la realidad constituyen el valor más importante de la empresa actual. Los responsables, tanto de los organismos emisores de normas como de la dirección y gestión de la empresa, deberían aceptar que sería mejor informar algo a que no se informe nada.

Es importante que en un futuro, quizá no muy lejano, el capital intelectual se incluya en las cuentas anuales. Aunque para llegar a esta situación habrá que afrontar una serie de obstáculos, siendo el más importante: afrontar un cambio de mentalidad, tanto de los distintos grupos emisores de normas como de los propios gestores de la empresa.

La profesión contable debería, en principio, divulgar información respecto a la medida del capital intelectual y a su forma de presentación, a fin de conseguir una homogenización. De esta manera, el usuario externo vería satisfecho de un modo más adecuado sus necesidades informativas de cara a la futura toma de decisiones. La contabilidad tiene que adaptarse a las nuevas circunstancias que caracterizan a la empresa, pues tiene ante sí un reto: seguir siendo útil al usuario.

La auditoría en cambio, en sus modernos enfoques operativo o integral, sí puede pronunciarse sobre el capital intelectual y, es más, puede llegar a sugerir correctivos y mejoras respecto de su utilización y sus efectos. Para ello, se deberá tener en cuenta una adecuada metodología que le permita medir la administración y gestión del capital intelectual.

\section{La Medición y Administración del Capital Intelectual}

Durante el segundo trimestre del año 2000 , Microsoft tuvo un valor de mercado de más de US $\$ 600$ billones, pero el valor en libros de sus activos fue de US\$ 45 billones, US\$22 billones de los cuales fueron activos circulantes. Con menos de US\$ 2 billones en activos fijos, Microsoft es el modelo de la nueva economía en la cual el valor de una compañía no se encuentra en activos físicos tales como ingresos, razones precio/utilidades, o participación en el mercado; sino, en capital intelectual, cultura organizacional, lealtad de clientes, y capital en marcas. Y Microsoft no está sola. Durante las últimas dos décadas la diferencia entre los valores de mercado y en libros de otras compañías ha alcanzado niveles sin precedentes. Una evidencia se aprecia en el siguiente cuadro publicado por la revista FORTUNE, en el cual se presenta una comparación en el año 1999 del valor de mercado y del valor en libros del capital de 500 compañías, de las que destacan nueve con diferencias importantes entre ambos valores: 


\begin{tabular}{|l|c|c|c|}
\hline \multicolumn{3}{|c|}{ VALOR DE MERCADO VERSUS VALOR EN LIBROS } \\
(BILLONES DE DÓLARES) \\
\hline \multicolumn{1}{|c|}{ COMPANÍ́A } & VALOR & VALOR & $\%$ DEL VALOR EN \\
& DEL MERCADO & EN LIBROS & LIBROS SOBRE EL \\
& & & DE MERCADO \\
\hline COCA COLA & $\$ 147,6$ & $\$ 6,2$ & $4 \%$ \\
MICROSOFT & 119,1 & 6,9 & $6 \%$ \\
GILLETTE & 45,2 & 4,5 & $10 \%$ \\
MERCK & 106,5 & 12,0 & $11 \%$ \\
PHILLIP MORRIS & 104,6 & 14,2 & $14 \%$ \\
P \& G & 85,4 & 11,7 & $14 \%$ \\
PEPSICO & 48,4 & 5,6 & $15 \%$ \\
INTEL & 113,2 & 16,9 & $18 \%$ \\
GENERAL ELECTRIC & 169,4 & 31,1 & $35 \%$ \\
FORTUNE 500 (TOTAL) & $\$ 5697,4$ & $\$ 1972,3$ & \\
\hline
\end{tabular}

En este cuadro se observa que el valor en libros del capital de las 500 empresas representa sólo el $35 \%$ del valor del mercado del mismo. Asimismo, en los casos de empresas como Coca Cola, Microsoft y Gillette, el valor contable del capital sólo representa el $4 \%, 6 \%$ y $10 \%$, respectivamente, por mencionar solamente algunas de estas empresas.

Otro caso ilustrativo de activos intangibles omitidos en el balance $y$, consecuentemente, del capital es el de la compañía "Time Warner", de la cual en su informe anual (memoria) de 1995 se menciona lo siguiente:

\section{"Activos omitidos en el Balance General}

Time Warner cree que el valor de ciertos activos son omitidos en el balance y que éstos deberian considerarse junto con otros factores, al momento de evaluar tanto la situación financiera de una compañía, como para tener una perspectiva del futuro relación a sus operaciones, incluyendo su capacidad de satisfacer sus requerimientos de capital y su liquidez.

Como creador $y$ distribuidor de información de marca y de derechos de autor en el mundo del espectáculo, Time Warner y el Entertainment Group, poseen un monto significativo de activos intangibles generados internamente $y$ cuyo valor no se refleja en sus balances generales consolidados. Estos activos intangibles se extienden a través de los principales intereses que Time Warner tiene en otras empresas, pero se ejemplifican de mejor forma en su colección de productos musicales con derechos de autor, en su interés mayoritario en Warner Bros y en HBO en los productos de la televisión y de la industria filmica, y en la creación o extensión de marcas, como es el caso de los nuevos títulos de la revista Time Inco 
de la cadena WB. Generalmente, los principios Como creador y distribuidor negocios o por compra.

Debido a que Time Warner posee los derechos de autor de este material creativo, continuamente genera ingresos a través de la venta de los productos por diversos medios de comunicación y en los mercados nuevos o ya existentes. El valor de una película, los derechos de autor para televisión, además de las marcas registradas, las series de televisión o las peliculas van a mercados secundarios $y$ se autorizan marcas como Looney Tunes y Batman en la industria del menudeo y en otros mercados. Además, los avances tecnológicos, tales como la introducción del disco compacto y las vídeo caseteras en los ochenta y la potencial versatilidad. del disco digital en el futuro, han generado históricamente oportunidades de captación de ingresos de manera considerable a través del relanzamiento $y$ venta de los productos incluyendo sus derechos de autor bajo un nuevo formato tecnológico. Por consiguiente, estos activos intangibles tienen un valor significativo que no se refleja plenamente en los estados financieros consolidados de Time Warner o del Entertainment Group.

Warner Bros, cuenta con contratos de venta a futuro que representan un monto de ingresos potenciales aún no registrados; que van desde contratos en efectivo hasta la autorización en teatro $y$ televisión para cable, cable básico y exhibiciones de televisión sindicadas, los cuales en 1995 ascendieron a 1.056 billones de dólares, comparados con 852 millones de dólares en 1994 (incluyendo los montos relativos a $\mathrm{HBO}$ de 175 millones en cada año).

Debido a que estos contratos son por autorizaciones teatrales y para television, el reconocimiento de los ingresos depende principalmente de la designación de periodos disponibles para salir al aire, tomando en cuenta los términos del contrato de autorización.

Por consiguiente, el monto de estos contratos a futuro no ha sido reconocido todavia en el balance, considerando como una futura fuente de financiamiento".

Como puede apreciarse, esta diferencia creciente surge debido a las organizaciones basadas en la cultura del conocimiento y a su dependencia sobre el capital intelectual que han modificado la forma en que contemplamos el proceso de creación de valor. Las mediciones financieras tradicionales tales como el rendimiento sobre el capital y las utilidades por acción -que miden lo que constituye la mayor parte de los sistemas administrativos de rendimiento corporativo- le dicen poco a los inversionistas y a la administración en cuanto al verdadero comportamiento de la compañía. Debido a que las prácticas contables no se han mantenido al mismo ritmo que la importancia creciente del capital intelectual, muchos de estos activos permanecen fuera de la vista, ajenos a la atención, fuera de los balances generales, y sin vigilancia. Sin herramientas para capturar y medir el capital intelectual, muchas empresas terminan administrando mal sus activos intelectuales, o lo que es peor, destruyendo el valor del conocimiento simplemente porque los administradores no comprenden la naturaleza de los recursos de la compañía.

Aunque los activos intelectuales pueden ser invisibles, ellos pueden administrarse, medirse y auditarse. Pero, si los gerentes y administradores desean cultivar los recursos intelectuales necesitan desarrollar mediciones del comportamiento que enlacen la productividad interna con el valor agregado de mercado y estados financieros 
prácticos que revelen y pongan al descubierto las mediciones de capital intelectual.

Las empresas y organizaciones que desarrollan mecanismos integrados para capturar y administrar estos recursos vitales estarán mejor preparadas para generar rendimientos sostenidos para los accionistas.

\section{Determinación del Valor del Capital Intelectual}

Sin duda, uno de los procedimientos más importantes de la auditoría del capital intelectual es la determinación del valor del capital intelectual. Los sistemas de medición del comportamiento basados en la contabilidad dominan tanto la evaluación de las compañías basadas en el mercado extemo como las evaluaciones internas de los administradores y las unidades estratégicas del negocio. Pero, estas herramientas contables simplemente no captan el valor del capital intelectual. La participación del capital en las marcas, la investigación y el desarrollo, y el capital humano -entre otras formas de capital intelectual- no aparecen en los balances generales.

Para compensar estas deficiencias contables algunos consultores y analistas han desarrollado mediciones diseñadas para captar mejor el valor para los accionistas. El valor agregado de mercado y el valor agregado económico, por ejemplo, son mediciones crecientemente populares, encaminadas hacia la creación de relevancia en los reportes financieros. Compañías tales como General Electric y Coca Cola se enfocan hacia el valor agregado de mercado como el principal indicador del comportamiento de sus negocios.

A pesar de la tendencia de calcular el valor agregado económico, pocos métodos son capaces de capturar el valor total del capital intelectual de una organización. Para conseguirlo, las firmas necesitan de una organización y, para conseguir ello, necesitan a su vez un sistema de medición encuadrado alrededor de los recursos que crean valor para la organización, un sistema que lleva en su núcleo los activos intelectuales necesarios para competir con éxito en el mercado global.

\section{Las Mediciones Importantes}

En años recientes, la comunidad inversionista ha ido más allá de las razones financieras fundamentales hacia los indicadores no financieros. Cada vez más, los inversionistas consideran que las mediciones financieras son indicadores rezagados de comportamientos, y los factores no financieros son los indicadores principales.

Pero, ¿cuáles son los principales indicadores no financieros y cómo se pueden medir? Un estudio de Ernst \& Young, firma internacional de auditoría, identificó las 10 importantes mediciones no financieras que le permitirán al auditor operativo e integral evaluar y examinar el capital intelectual. Estas mediciones reflejan el punto de vista que esos recursos, y no los productos, constituyen la fuente primaria de ventaja competitiva.

Estos diez (10) indicadores son: 


\section{Mediciones No Financieras de la} Auditoría del Capital Intelectual

1.- Ejecución estratégica

2.- Credibilidad administrativa

3.- Calidad de estrategia

4.- Innovación

5.- Capacidad de atraer gente talentosa

6.- Participación de mercado

7.- Experiencia administrativa

8.- Calidad de compensación ejecutiva

9.- Calidad de procesos importantes; $y$

10.- Liderazgo de investigación

Los recursos específicos incluyen marcas, contactos comerciales, personal calificado, acceso al capital y cosas parecidas. En forma notable, ninguno de estos recursos aparece expresado directamente en los estados financieros.

Pero, ello no impulsa la ventaja competitiva de una empresa. Como resultado, las compañías necesitan su identificación y administración. Los sistemas contables, para los recursos intelectuales, deberán vigilar la acumulación, mantenimiento y disponibilidad de los recursos. Una vigilancia y supervisión de alto nivel permitirá a las firmas controlar tanto la disponibilidad de los recursos como su despliegue estratégico.

La actividad basada en el costeo representa, quizá, el paso más significativo hacia la medición del comportamiento con base en los recursos. Durante la última década, el ABC (Actividad Bancaria en el Costeo) ha revolucionado el costeo de los productos al relacionar el costo de los mismos con los recursos materiales, financieros, humanos y de tiempo que se integran dentro del producto. El ABC permite a las compañías determinar el costo y el valor relativo de sus productos para luego aplicar la reingeniería en los procesos subyacentes para lograr mayor eficiencia. Y, sin embargo, la actividad basada en el costeo y la reingeniería del proceso constituyen solamente la punta del iceberg.

Ellos no hacen un buen trabajo al captar y medir los recursos básicos tales como los costos del producto y del periodo, sino que omiten el valor de los activos intelectuales como investigación y desarrollo, sistemas de información y otras funciones especializadas. Un verdadero sistema, basado en los recursos, debe capturarlos completamente y luego ayudar a conformar las estrategias corporativas. Simplemente al aumentar el número y volumen de las mediciones para hacer anotaciones en los registros no representa un avance. Esto se logra al integrar estas mediciones y luego mejorarlas.

\section{CONCLUSIÓN}

- La habilidad de crear la innovación, servicio, crecimiento y el hecho de compartir el conocimiento son factores determinantes que agregan valor a la empresa, sin importar que ésta sea pública o privada.

- Los estados financieros no son los indicadores completos de la situación y la salud financiera de una empresa. Sin embargo, los inversionistas, banqueros y proveedores tratan de confiar en ellos.

- Los estados financieros muestran los cambios ocurridos en los activos tangibles de una empresa, pero son inadecuados para reportar los activos intangibles.

- Para ser realista y brindar valor agregado, la auditoría operativa e integral debe 
enfocar el examen de modo que evalúe el capital intelectual, cuyos resultados deben incluirse en el informe de auditoría.

BIBLIOGRAFĹA

NOAH P. BARSKY y GARRY MARCHANT, (Colaboradores de la Publicación Strategic Finance).

"El recurso más valioso".

BROOKING, A.

"El capital intelectual: el principal activo de las empresas del tercer milenio".

WHITNEY, John.

"Hay un rinoceronte en la sala". Director del Columbia Business School's Center.

Artículo publicado por AECA (Resumen realizado por Montserrat Sierra Fer- nández y publicado en el Diario Oficial El Peruano el 29 Mayo 2000, p. 24).

KENNETH A. BIGGS.

"El eslabón perdido de la contabilidad el capital intelectual no registrado". 